\title{
Vectors and malaria transmission in deforested, rural communities in north-central Vietnam
}

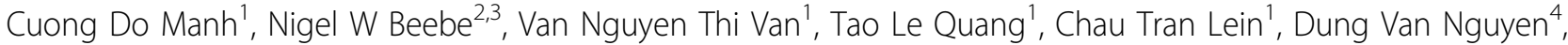 \\ Thanh Nguyen Xuan ${ }^{1}$, Anh Le Ngoc ${ }^{1}$, Robert D Cooper ${ }^{5^{*}}$
}

\begin{abstract}
Background: Malaria is still prevalent in rural communities of central Vietnam even though, due to deforestation, the primary vector Anopheles dirus is uncommon. In these situations little is known about the secondary vectors which are responsible for maintaining transmission. Basic information on the identification of the species in these rural communities is required so that transmission parameters, such as ecology, behaviour and vectorial status can be assigned to the appropriate species.
\end{abstract}

Methods: In two rural villages - Khe Ngang and Hang Chuon - in Truong Xuan Commune, Quang Binh Province, north central Vietnam, a series of longitudinal entomological surveys were conducted during the wet and dry seasons from 2003 - 2007. In these surveys anopheline mosquitoes were collected in human landing catches, paired human and animal bait collections, and from larval surveys. Specimens belonging to species complexes were identified by PCR and sequence analysis, incrimination of vectors was by detection of circumsporozoite protein using an enzyme-linked immunosorbent assay.

Results: Over $80 \%$ of the anopheline fauna was made up of Anopheles sinensis, Anopheles aconitus, Anopheles harrisoni, Anopheles maculatus, Anopheles sawadwongporni, and Anopheles philippinensis. PCR and sequence analysis resolved identification issues in the Funestus Group, Maculatus Group, Hyrcanus Group and Dirus Complex. Most species were zoophilic and while all species could be collected biting humans significantly higher densities were attracted to cattle and buffalo. Anopheles dirus was the most anthropophilic species but was uncommon making up only 1.24\% of all anophelines collected. Anopheles sinensis, An. aconitus, An. harrisoni, An. maculatus, An. sawadwongporni, Anopheles peditaeniatus and An. philippinensis were all found positive for circumsporozoite protein. Heterogeneity in oviposition site preference between species enabled vector densities to be high in both the wet and dry seasons allowing for year round transmission.

Conclusions: In rural communities in north central Vietnam, malaria transmission was maintained by a number of anopheline species which though collected feeding on humans were predominantly zoophilic, this behaviour allows for low level but persistent malaria transmission. The important animal baits - cattle and buffalo - were kept in the village and barrier spraying around these animals may be more effective at reducing vector densities and longevity than the currently used indoor residual spraying.

\section{Background}

Malaria is endemic in many parts of Vietnam and up until the 1990s was a major public health problem. Since then a concerted effort by the government through the distribution of insecticide-treated nets and wide spread availability of artesunate treatment has

\footnotetext{
* Correspondence: bob.cooper@defence.gov.au

${ }^{5}$ Australian Army Malaria Institute, Gallipoli Barracks, Enoggera, Queensland 4051, Australia

Full list of author information is available at the end of the article
}

significantly reduced transmission [1-3]. Much of the morbidity and mortality that now remains is associated with forest malaria in the central highland regions of the country where Anopheles dirus, an efficient vector of malaria, is common [4-6].

While the control of An. dirus and forest malaria is a significant problem for Vietnam there are still many rural areas throughout the country where, though the land has been cleared for cultivation and An. dirus is uncommon, malaria still persists. In these deforested

\section{Biomed Central}


areas, in the absence of An. dirus, other species - Anopheles minimus s.l., Anopheles aconitus, Anopheles maculatus s.l., and Anopheles sinensis - have been considered responsible for malaria transmission. However there is little published data confirming the identification of these species or their distribution and thus there is little known about their ecology, behavior and the vectorial status.

Acquiring the relevant epidemiological information pertaining to these species and confirmation of their role in transmission has been impeded by the presence of cryptic species within many of the suspected vector taxa. This has recently been resolved for a number of these complexes and reliable molecular techniques are now available allowing the accurate identification of the various complex members. Molecular based techniques have been developed for the identification of members of the An. dirus [7,8], An. minimus [9], An. maculatus [10], Anopheles annularis [11], and Anopheles sundaicus [12], groups and complexes and thus it is now possible to conduct field studies to determine their distribution, ecology, behavior, and role in malaria transmission.

Truong Xuan Commune in Quang Binh Province (north central Vietnam) is typical of many rural communities in Vietnam where the forest surrounding the villages has been cleared for timber and cultivation, the primary malaria vector - $A n$. dirus - is uncommon yet a low level of malaria persists throughout the year. Transmission occurs within the village, and while some forest still remains on the surrounding hills no agricultural activities occur there. These forests are only visited for the purposes of timber cutting, hunting, and food gathering; these transient activities do not allow the existence of forest malaria [6]. In Truong Xuan little is known about the vectors of malaria, to resolve this, entomological surveys were conducted in two villages in the Commune over the period 2003-2007; the findings of these surveys are reported here.

\section{Methods}

\section{Study site}

Truong Xuan Commune in Quang Binh Province is located $17^{\circ} 17^{\prime} \mathrm{N}$ and $106^{\circ} 37^{\prime} \mathrm{E}$, and is approximately $500 \mathrm{~km}$ south of Hanoi. The commune consists of several villages, including the two study sites: Hang Chuon village (26 houses, population approximately 100) and Khe Ngang village (48 houses, population approximately 200). These two villages are $15 \mathrm{~km}$ inland and lie in a river valley ( $17 \mathrm{~m}$ above sea level) surrounded by limestone mountains. Hang Chuon and Khe Ngang are 2 $\mathrm{km}$ apart and separated by mountains, but connected by a narrow pass. A river flows through this pass and through both villages. The river is fed by numerous small streams which are slow flowing even in the wet season but are reduced to small interconnected pools in the dry season. The climate of the region is tropical monsoon with distinct wet and dry seasons. The area receives about $1,960 \mathrm{~mm}$ of rain per annum (median for 1993-2002) with 70\% occurring during the wet season from August to December; rain during this period can be intense and cause local flooding. Mean temperatures (mean of $\max / \mathrm{min}$ over $10 \mathrm{yr}$ ) range from $17.1^{\circ} \mathrm{C}$ in February to $29.7^{\circ} \mathrm{C}$ in July.

Hang Chuon is slightly undulating, around both villages the original forest has been cleared for cultivation, which consists mainly of cassava, corn, and melons; rice is grown around Khe Ngang. A variety of blood sources exist for mosquitoes and while all households have dogs and chickens the larger blood sources are humans, cattle, and buffalo. Cattle and buffalo free range during the day, when not used for work, but at night are penned or tethered near the owner's house (within $15 \mathrm{~m}$ ). Most houses in Khe Ngang are rendered brick while in Hang Chuon, which appears less affluent, many of the houses are of a more traditional style, raised off the ground (1$2 \mathrm{~m}$ ) and of very loose or open constructions with walls of woven bamboo or cane matting. Insecticide treated bed nets are provided by the government and indoor residual spraying with permethrin has been carried out once a year since 2002. The villages are serviced by the Commune Health Station which is about $6 \mathrm{~km}$ from Khe Ngang and $8 \mathrm{~km}$ from Hang Chuon. Malaria diagnosis is by blood-slide microscopy and free treatment a seven day course of artesunate - is provided, though compliance is not observed. In the villages health workers also provide treatment for symptomatic cases.

\section{Incidence of malaria}

The incidence of malaria was determined by passive case detection through the Commune Health Station. Diagnosis was by microscopy, based on examination of 100 thick film fields of a Giemsa-stained slide (4\% and stained for 45 minutes). Positive slides were then read against 200 white blood cells (presuming 8-10 WBC/ thick film field) to determine species and parasite density (parasite density was scored as:,,,++++++++++ ). The clinic maintained comprehensive records of the name, age, sex, village, slide positivity and species of Plasmodium.

There is no transport system throughout the commune and while push bike and motor bike ownership is not uncommon, a visit to the Health Station could involve a walk of up to $20 \mathrm{~km}$. The Commune Health Station is supported by village health workers who operate at the village level and who diagnoses and treat malaria cases based on symptoms. 


\section{Anopheline collections}

Four collection methods were employed: human landing catches (HCL); paired collections off humans and buffalo; simultaneous collections off humans, cattle, and buffalo; and larval collections. These were performed as follows.

Human landing collections were made in Khe Ngang village during the wet seasons (September - October) of 2003 and 2004 and similar HLC were carried out in Hang Chuon village during the wet seasons of 2004 and 2005. These HLC were made by four collectors in each village, all collectors worked outdoors. Each collector caught all anophelines landing on the lower legs and feet for 50 minutes each hour from 6 pm - 6 am. All catches were held in cups labelled for the hour; the mosquitoes were killed by freezing and identified the following morning.

At Khe Ngang collections were made over 27 nights over the two wet season; rain interrupted collections at Hang Chuon and the number of collection nights varied from 14 - 27 nights over two wet seasons.

Paired anopheline collections off buffalo and human baits were performed at Khe Ngang village for 10 nights over the wet seasons (September - October) of 2004 and 2005. Collections were made hourly from 6 pm - 6 am, with one collector collecting off two tethered buffalo and by one collector sitting $15 \mathrm{~m}$ away collecting off himself. All collections were for $50 \mathrm{~min}$ each hour and, for the human bait, performed as described above for the HLC. Collections from the buffalo were made by searching the surrounding vegetation (within $2 \mathrm{~m}$ of the animals) for resting anophelines. All mosquitoes were held separately by hour and bait type, killed by freezing and identified the following morning.

Simultaneous anopheline collections were made off human, buffalo, and cattle baits at Hang Chuon village for 14 nights during the wet season of 2006 and for 14 nights during the dry season (April - May) of 2007. The collections were made by six collectors, two collecting off cattle, two collecting off buffalo, and two collecting off themselves; the collections were made for two hours from $8 \mathrm{pm}-10 \mathrm{pm}$. Anophelines were collected and processed as described above.

A search for anopheline larvae was made within 1$2 \mathrm{~km}$ of Khe Ngang and Hang Chuon villages during the wet and dry seasons 2005-2007. All larvae collected were reared to adults and identified. A description of the oviposition site was recorded.

All specimens from the adult and larval collections were held frozen $\left(-20^{\circ} \mathrm{C}\right)$ in the field, transported back to the laboratory on dry ice $\left(-70^{\circ} \mathrm{C}\right)$ and stored at this temperature until being analysed for the presence of circumsporozoite protein or by PCR for species identification.

\section{Species identification}

All specimens were identified in the field using the national key - Identification Key for Anopheles in Vietnam 1987 - prepared by the Institute of Malaria, Parasitology and Entomology, Hanoi.

Specimens belonging to the Hyrcanus Group, Funestus Group, Maculatus Complex, and Dirus complex were further analysed using the Internal Transcribed Spacer region 2 (ITS2) of the ribosomal DNA by either polymerase chain reaction - restriction fragment length polymorphism (PCR-RFLP) or allele-specific PCR analyses as well as DNA sequencing. For RFLP analysis, DNA was extracted, the ITS2 region amplified, digested with an appropriate restriction enzyme and the RFLP generated separated and visualized using previously described methods [13,14]. Additional methods were used to resolve the identification of the members of the Dirus Complex [8], the Funestus Group [9], and the Maculatus Group [10]. All PCR-based methods for species identification were validated by DNA sequencing individuals representing each species-specific product and comparing the ITS2 sequences with those listed in GenBank.

\section{Vector incrimination}

The head and prothorax of specimens collected off human, cattle, and buffalo baits were processed for the presence of circumsporozoite protein of Plasmodium falciparum and Plasmodium vivax using an enzyme linked immunoabsorbent assay (ELISA) and the protocol of Dr Robert Wirtz (Centers for Disease Control and Prevention, MS F42, Atlanta, GA 30341-3717, USA). Specimens were considered positive if the absorbance value recorded was twice that of the average of the negative controls and all positive samples were rerun for confirmation.

\section{Results}

\section{Malaria incidence in Truong Xuan}

Between 2002 and 2006, 509 malaria cases reported to the Health Station - an average of 102 per annum and indicating an annual parasite rate of $6.9 \%(102 / 1467)$ for the Commune. This though was likely to be an underestimate of the malaria situation as some people self medicated or were treated in the village and others who were asymptomatic or who only had mild symptoms would not travel the distance to the Commune Health Station; all these cases go unreported. Malaria does not occur evenly throughout the commune and of the several villages that make up Truong Xuan Commune the range of malaria cases was 4 to 136 . Hang Chuon and Khe Ngang, two of the more remote villages, had the highest incidences of transmission making up $26.7 \%$ (136/509) and $14.1 \%(72 / 509)$ of the cases recorded respectively. 
In these two villages adult females and children $(<9 \mathrm{yr})$ accounted for $60.3 \%$ of the malaria indicating that transmission was occurring in the villages as these inhabitants stay in the village at night.

Of the 509 cases $71.9 \%$ were P. falciparum and $28.1 \%$ $P$. vivax; malaria transmission occurred all year round but peaked during the wet season in the month of October (Figure 1).

\section{Anopheline identification}

Of the mosquitoes collected many were identified as belonging to complexes or groups of species which were difficult to separate using morphological characters provided in the national key. For the anophelines at Truong Xuan Commune molecular analysis redefined species composition, condensing some groups and revealing cryptic species in others.

From the collections made in Khe Ngang and Hang Chuon the following members of the Hyrcanus Group were identified by morphology: An. sinensis, Anopheles peditaeniatus, Anopheles crawfordi, Anopheles nigerrimus, Anopheles argyropus, Anopheles lesteri, and Anopheles nitidus (= Anopheles indiensis by the national key). Using the amplified ribosomal ITS2 region and digesting with the restriction enzyme Dde I, diagnostic restriction fragments length polymorphisms (RFLP) were produced that resolved these eight species to $A n$. sinensis, An. peditaeniatus, and An. crawfordi (Table 1). The ITS2 regions of individuals representing each of these species were sequenced and the sequences matched to those on GenBank confirming the species as indicated. In Khe Ngang the proportion of An. sinensis, An. peditaeniatus, and An. crawfordi was $92.0 \%, 7.6 \%$
Table 1 Resolution of identification by PCR-RFLP for members of the Hyrcanus Group collected in Khe Ngang village

\begin{tabular}{lcccc}
\hline \multirow{2}{*}{ Species } & \multicolumn{4}{c}{ Identification by: } \\
\cline { 2 - 5 } & Morphology & \multicolumn{3}{c}{ PCR-RFP } \\
\cline { 3 - 5 } & & $\begin{array}{c}\text { An. } \\
\text { sinensis }\end{array}$ & $\begin{array}{c}\text { An. } \\
\text { peditaeniatus }\end{array}$ & $\begin{array}{c}\text { An. } \\
\text { crawfordi }\end{array}$ \\
\hline An. sinensis & 1379 & 1353 & 24 & 2 \\
An. & 104 & 40 & 64 & 0 \\
peditaeniatus & & & & \\
An. nigerrimus & 75 & 44 & 29 & 2 \\
An. crawfordi & 23 & 19 & 1 & 3 \\
An. nitidus & 34 & 33 & 1 & 0 \\
An. argyropus & 11 & 7 & 4 & 0 \\
An. lesteri & 22 & 20 & 2 & 0 \\
$\quad$ Total & 1648 & 1516 & 125 & 7 \\
$\quad \%$ & & $92.0 \%$ & $7.6 \%$ & $0.4 \%$ \\
\hline
\end{tabular}

and $0.4 \%$ respectively $(\mathrm{n}=1,648)$, in Hang Chuon: $56.2 \%, 43.8 \%$ and $0 \%$ respectively $(\mathrm{n}=130)$.

Three members of the Funestus Group were identified in the collections: $A n$. minimus s.l. of the Minimus Complex, An. aconitus, and Anopheles jeyporiensis. Morphologically the white scaling on the apical half of the proboscis reliably identified $A n$. aconitus. Following molecular analysis the majority of $A n$. minimus s.l. were found to be Anopheles harrisoni with only a small number of An. minimus; of the 20 An. jeyporiensis collected only one belonged to this species, the remainder were An. harrisoni (Table 2).

In the national key the only member of the Maculatus Group described in Vietnam is An. maculatus. Of 2,121 specimens of this species collected in Hang Chuon and

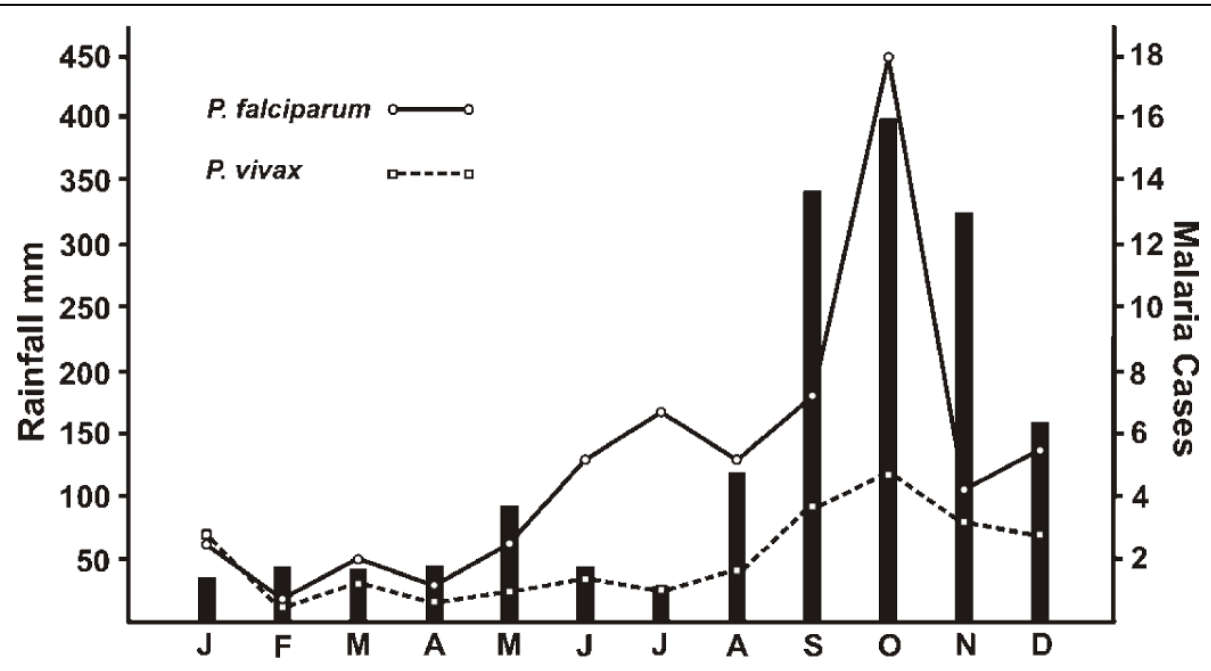

Figure 1 Monthly rain fall data (mean of 10 years) and the mean monthly incidence of malaria (2003-2007) for Truong Xuan Commune. 
Table 2 Resolution of identification by PCR-RFLP for members of the Funestus Group collected in Hang Chuon village

\begin{tabular}{lccccc}
\hline & \multicolumn{5}{c}{ Identification by: } \\
\cline { 2 - 6 } Species & & \multicolumn{4}{c}{ PCR } \\
\cline { 2 - 6 } & Morphology & An. minimus & An. harrisoni & An. aconitus & An. jeyporiensis \\
\hline An. minimus s.l. & 1034 & 15 & 1017 & 1 & 1 \\
An. jeyporiensis & 20 & 0 & 19 & 0 & 1 \\
An. aconitus & 1152 & 1 & 1 & 1150 & 0 \\
\hline
\end{tabular}

Khe Ngang and analysed by PCR-RFLP $47.2 \%$ were found to be $A n$. maculatus and $52.8 \%$ were An. sawadwongporni. The restriction enzyme Hsp92 II was found to produce diagnostic RFLP for separating these two species, this outcome was confirmed by sequencing and matching to existing sequences in GenBank.

Of $63 A n$. dirus s.l. specimens analysed by PCR-RFLP all were $A n$. dirus (formerly $A n$. dirus A); seven specimens identified morphologically as Anopheles takasagoensis were also found to be An. dirus.

\section{Species composition and host preference}

From 2003 to 2007, 10,078 anophelines were collected off human and animal baits. Using morphology and molecular analysis 21 species were identified from this material (Table 3). Six species: An. sinensis, An. aconitus,

Table 3 Anopheles species and numbers collected off human and animal (buffalo and cow) baits during 20032007 in Khe Ngang and Hang Chuon villages

\begin{tabular}{|c|c|c|c|c|}
\hline \multirow[t]{2}{*}{ Species (abbreviation) } & \multicolumn{2}{|c|}{ Bait } & \multirow[t]{2}{*}{ Total } & \multirow[t]{2}{*}{$\%$} \\
\hline & Human & Animal & & \\
\hline An. sinensis (sin) & 709 & 1792 & 2501 & 25.01 \\
\hline An. aconitus (aco) & 171 & 1266 & 1437 & 14.37 \\
\hline An. harrisoni (har) & 71 & 938 & 1009 & 10.09 \\
\hline An. maculatus (mac) & 285 & 877 & 1162 & 11.62 \\
\hline An. sawadwongporni (saw) & 424 & 764 & 1188 & 11.88 \\
\hline An. philippinensis (phil) & 72 & 749 & 821 & 8.21 \\
\hline An. vagus (vag) & 8 & 578 & 586 & 5.86 \\
\hline An. annularis (ann) & 37 & 418 & 455 & 4.55 \\
\hline An. kochi (koc) & 4 & 326 & 330 & 3.30 \\
\hline An. peditaeniatus (ped) & 11 & 192 & 203 & 2.03 \\
\hline An. nivipes (niv) & 5 & 166 & 171 & 1.71 \\
\hline An. dirus (dir) & 111 & 13 & 124 & 1.24 \\
\hline An. barbirostris (bar) & 2 & 36 & 38 & 0.38 \\
\hline An. minimus (min) & 5 & 14 & 19 & 0.19 \\
\hline An. umbrosus (umb) & 0 & 8 & 8 & 0.08 \\
\hline An. crawfordi (cra) & 0 & 8 & 8 & 0.08 \\
\hline An. separatus (sep) & 0 & 7 & 7 & 0.07 \\
\hline An. jamesi (jam) & 2 & 2 & 4 & 0.04 \\
\hline An. tessellatus (tes) & 2 & 2 & 4 & 0.04 \\
\hline An. jeyporiensis (jey) & 0 & 2 & 2 & 0.02 \\
\hline An. gigas (gig) & 1 & 0 & 1 & 0.01 \\
\hline Totals & 1920 & 8158 & 10078 & 100 \\
\hline
\end{tabular}

An. harrisoni, An. maculatus, An. sawadwongporni and An. philippinensis were the most common and accounted for $80.5 \%$ of all the specimens collected. While all species, except for some of the less common ones (< 10 specimens collected), were collected from humans the majority $(80.94 \%)$ of specimens were collected off non-human (cattle and buffalo) baits (Table 3 ). Of the species common to both villages, those in Hang Chuon appeared to be more zoophilic than those in Khe Ngang (Tables 4 and 5). Only An. dirus showed anthropophilic tendencies, though the numbers of this species collected in human and animal bait studies was low. Anopheles sawadwongporni, An. sinensis, and $A n$. maculatus were the least zoophilic of the other species while $A n$. philippinensis, An. vagus, An. kochi, $A n$. nivipes, and $A n$. harrisoni were strongly zoophilic (Tables 4 and 5). In Hang Chuon village a comparison between the host attractiveness of buffalo or cattle indicated that most species preferred to feed off cattle or had no preference at all (Table 5). Only An. philippinensis appeared to have a preference for buffalo but this was not statically significant $\left(\chi^{2}=3.38, \mathrm{P}=0.1\right)$.

Table 4 Anopheles species and numbers collected simultaneously off human and buffalo baits in Khe Ngang village during the wet seasons of 2004 and 2005

\begin{tabular}{lccc}
\hline & \multicolumn{3}{c}{ Bait type } \\
\cline { 2 - 4 } Species & Human & Buffalo & Al \\
\hline An. sawadwongporni & 9 & 30 & 0.300 \\
An. maculatus & 4 & 48 & 0.083 \\
An. harrisoni & 2 & 60 & 0.033 \\
An. sinensis & 60 & 1852 & 0.024 \\
An. aconitus & 26 & 1163 & 0.022 \\
An. vagus & 2 & 110 & 0.018 \\
An. annularis & 6 & 349 & 0.017 \\
An. kochi & 2 & 126 & 0.015 \\
An. philippinensis & 6 & 524 & 0.011 \\
An. dirus & 4 & 0 & - \\
An. nivipes & 0 & 8 & - \\
An. peditaeniatus & 0 & 41 & - \\
An. barbirostris & 0 & 24 & - \\
An. crawfordi & 0 & 8 & - \\
\hline Colections & & &
\end{tabular}

Collections were made from $6 \mathrm{pm}$ - 6am over 10 nights. Note $\mathrm{Al}$ is the anthropophilic index (human bait/animal bait). 
Table 5 Anopheles species and numbers collected simultaneously off human, cattle and buffalo baits in Hang Chuon village

\begin{tabular}{lccccc}
\hline & \multicolumn{5}{c}{ Bait type } \\
\cline { 2 - 6 } Species & Human & Cattle & Buffalo & $\chi^{\mathbf{2}}$ & Al \\
\hline An. dirus & 9 & 8 & 5 & 0.346 & 0.692 \\
An. sawadwongporni & 33 & 528 & 206 & $70.63^{* *}$ & 0.045 \\
An. sinensis & 1 & 28 & 17 & 1.34 & 0.022 \\
An. peditaeniatus & 1 & 29 & 19 & 1.04 & 0.021 \\
An. maculatus & 14 & 504 & 327 & $18.85^{* *}$ & 0.017 \\
An. philippinensis & 1 & 93 & 132 & 3.38 & 0.004 \\
An. harrisoni & 2 & 503 & 375 & $9.33^{*}$ & 0.002 \\
An. aconitus & 0 & 62 & 41 & 2.14 & - \\
An. annularis & 0 & 36 & 33 & 0.065 & - \\
An. barbirostris & 0 & 9 & 3 & - & - \\
An. jamesi & 0 & 1 & 1 & - & - \\
An. kochi & 0 & 129 & 71 & $8.41^{*}$ & - \\
An. minimus & 0 & 6 & 3 & - & - \\
An. nivipes & 0 & 4 & 4 & - & - \\
An. tessellatus & 0 & 2 & 0 & - & - \\
An. umbrosus & 0 & 0 & 3 & - & - \\
An. vagus & 0 & 300 & 168 & $18.61^{* *}$ & - \\
\hline
\end{tabular}

Collections were made from $8 \mathrm{pm}-10 \mathrm{pm}$ over 28 nights ( 14 nights during the wet season of 2006 and 14 nights during the dry season of 2007). Note $\chi^{2}$ is a comparison of the attractiveness of cattle and buffalo for the various species of anophelines, with * significant at $\mathrm{P}<0.05$ and ${ }^{*}$ significant at $\mathrm{P}<$ 0.001 .

Species composition and heterogeneity between villages Hang Chuon and Khe Ngang are only $2 \mathrm{~km}$ apart and there was no one species unique to either village. However abundance of the various species did vary. In Khe Ngang An. sinensis, An. aconitus, and An. philippinensis were the three most common species collected in HLC, while at Hang Chuon An. sawadwongporni, An. maculatus, and $A n$. dirus were the three most common species collected in HLC (Tables 6 and 7).

\section{Seasonality}

In Hang Chuon, for some species, abundance differed depending upon the season. Most species were more common in the wet season, notably An. sawadwongporni, An. philippinensis, and An. vagus. Whereas, An. harrisoni, An. sinensis, and to some extent An. aconitus were more prolific in the dry season. However, Anopheles maculatus, An. dirus, and An. peditaeniatus numbers appeared to be unaffected by rainfall patterns (Table 8).

\section{Feeding behaviour}

The night feeding pattern for the common species coming to human and buffalo baits are shown in Tables 9 and 10 and human landing catches throughout the night are shown in Table 11 for the common species in Khe
Table 6 Human landing catch rates for Anopheles species in Khe Ngang village during the wet seasons (September October) of 2003 and 2004

\begin{tabular}{lc}
\hline & Khe Ngang \\
\cline { 2 - 2 } Species & landing/person/night \\
\hline An. sinensis & 12.42 \\
An. aconitus & 1.91 \\
An. philippinensis & 1.01 \\
An. annularis & 0.58 \\
An. sawadwongporni & 0.34 \\
An. harrisoni & 0.27 \\
An. maculatus & 0.22 \\
An. vagus & 0.20 \\
An. dirus & 0.18 \\
An. kochi & 0.07 \\
An. nivipes & 0.07 \\
An. tessellatus & 0.04 \\
An. barbirostris & 0.02 \\
An. minimus & 0 \\
An. peditaeniatus & 0 \\
All species & 13.55 \\
\hline
\end{tabular}

Ngang and Table 12 for those in Hang Chuon. Feeding patterns off humans and animals appeared similar for the same species. Some species - An. sinensis, An. annularis, An. aconitus, An. philippinensis, An. nivipes, and An. vagus - fed throughout the night commencing at sunset and rising to a peak at about midnight $(11 \mathrm{pm}-1$ $\mathrm{am}$ ) and then remaining high until just before dawn. While others - An. maculatus, An. sawadwongporni,

Table 7 Human landing catch rates for Anopheles species in Hang Chuon village during the wet seasons (September - October) of 2004 and 2005

\begin{tabular}{lc}
\hline & Hang Chuon \\
\cline { 2 - 2 } Species & landing/person/night \\
\hline An. sawadwongporni & 4.68 \\
An. maculatus & 3.06 \\
An. dirus & 1.29 \\
An. aconitus & 0.69 \\
An. harrisoni & 0.60 \\
An. philippinensis & 0.20 \\
An. sinensis & 0.19 \\
An. peditaeniatus & 0.13 \\
An. annularis & 0.06 \\
An. minimus & 0.06 \\
An. vagus & 0.06 \\
An. barbirostris & 0.01 \\
An. nivipes & 0.01 \\
An. kochi & 0 \\
An. tessellatus & 0 \\
All species & 10.06
\end{tabular}


Table 8 Comparison of Anopheles species and numbers collected off human, cattle, and buffalo baits during the wet season and dry season

\begin{tabular}{lccc}
\hline Species & $\begin{array}{c}\text { Collected in dry } \\
\text { season }\end{array}$ & $\begin{array}{c}\text { Collected in wet } \\
\text { season }\end{array}$ & $\boldsymbol{\chi}^{\mathbf{2}}$ \\
\hline An. aconitus & 65 & 38 & 3.539 \\
An. annularis & 12 & 57 & $14.674^{* *}$ \\
An. barbirostris & 11 & 1 & $4.167^{*}$ \\
An dirus & 10 & 12 & 0.090 \\
An. kochi & 79 & 121 & $4.410^{*}$ \\
An. maculatus & 415 & 416 & 0.0006 \\
An. & 83 & 651 & $219.77^{* *}$ \\
sawadwongporni & & & \\
An. harrisoni & 759 & 121 & $232.53^{* *}$ \\
An. minimus & 7 & 2 & - \\
An. nivipes & 5 & 3 & - \\
An. peditaeniatus & 22 & 27 & 0.225 \\
An. philippinensis & 29 & 197 & $62.442^{* *}$ \\
An. sinensis & 41 & 5 & $14.086^{* *}$ \\
An. tessellatus & 1 & 1 & - \\
An. umbrosus & 3 & 0 & - \\
An. vagus & 78 & 390 & $104.00^{* *}$ \\
Total & 1620 & 2042 & \\
\hline Collentions wer mate & & &
\end{tabular}

Collections were made over 14 nights in the wet season of 2006 and 14 nights in the dry season of 2007 in Hang Chuon village. Note $\chi^{2}$ is a comparison of wet and dry season collections for each species where * indicates significance at $\mathrm{P}<0.05$ and ${ }^{* *}$ a significance at $\mathrm{P}<0.001$

An. dirus, and to some extent An. harrisoni, tended to seek a host early in the evening with human landing catches peaking between $6 \mathrm{pm}-9 \mathrm{pm}$. All mosquitoes left the vicinity of the animal bait immediately at first

Table 9 Anopheline collections off human baits in Khe Ngang village during the wet seasons (SeptemberOctober) of 2004 and 2005

\begin{tabular}{ccccccccccc}
\hline & \multicolumn{8}{c}{ Species collected landing on human bait } \\
\cline { 2 - 10 } Hour & sin & ann & aco & phil & mac & saw & har & koc & vag & dir \\
\hline $6-7$ & 4 & 1 & 0 & 0 & 1 & 0 & 1 & 0 & 1 & 1 \\
$7-8$ & 5 & 1 & 2 & 0 & 0 & 1 & 0 & 0 & 0 & 1 \\
$8-9$ & 2 & 0 & 3 & 1 & 1 & 0 & 0 & 0 & 0 & 0 \\
$9-10$ & 4 & 1 & 4 & 1 & 0 & 1 & 0 & 0 & 0 & 0 \\
$10-11$ & 9 & 1 & 7 & 0 & 1 & 0 & 0 & 0 & 0 & 0 \\
$11-12$ & 5 & 0 & 2 & 0 & 0 & 0 & 0 & 0 & 0 & 0 \\
$12-1$ & 8 & 0 & 2 & 2 & 0 & 0 & 0 & 2 & 0 & 1 \\
$1-2$ & 9 & 1 & 2 & 0 & 1 & 3 & 0 & 0 & 1 & 1 \\
$2-3$ & 5 & 1 & 3 & 1 & 0 & 2 & 0 & 0 & 0 & 0 \\
$3-4$ & 5 & 0 & 1 & 0 & 0 & 1 & 1 & 0 & 0 & 0 \\
$4-5$ & 1 & 0 & 0 & 1 & 0 & 1 & 0 & 0 & 0 & 0 \\
$5-6$ & 3 & 0 & 0 & 0 & 0 & 0 & 0 & 0 & 0 & 0 \\
Totals & 60 & 6 & 26 & 6 & 4 & 9 & 2 & 2 & 2 & 4 \\
\hline
\end{tabular}

Collections were conducted hourly from $6 \mathrm{pm}$ to $6 \mathrm{am}$ over 10 nights collections were made simultaneously with collections off buffalo bait see Table 10. Total number of specimens collected $=121$; of the 60 An. sinensis collected all were An. sinensis.
Table 10 Anopheline collections off buffalo baits in Khe Ngang village during the wet seasons (SeptemberOctober) of 2004 and 2005

\begin{tabular}{|c|c|c|c|c|c|c|c|c|c|c|c|}
\hline \multirow[b]{2}{*}{ Hour } & \multicolumn{11}{|c|}{ Species collected from buffalo bait } \\
\hline & $\sin$ & ann & aco & phil & niv & mac & saw & har & bar & koc & vag \\
\hline $6-7$ & 108 & 6 & 19 & 10 & 4 & 4 & 0 & 4 & 6 & 6 & 1 \\
\hline $7-8$ & 111 & 32 & 34 & 35 & 11 & 6 & 5 & 6 & 3 & 16 & 8 \\
\hline 8-9 & 137 & 16 & 44 & 32 & 28 & 8 & 3 & 5 & 2 & 6 & 7 \\
\hline $9-10$ & 135 & 20 & 61 & 61 & 15 & 8 & 4 & 1 & 2 & 4 & 24 \\
\hline $10-11$ & 148 & 27 & 135 & 50 & 12 & 3 & 3 & 4 & 3 & 18 & 9 \\
\hline $11-12$ & 188 & 50 & 141 & 58 & 2 & 4 & 4 & 9 & 3 & 15 & 12 \\
\hline $12-1$ & 183 & 34 & 140 & 66 & 13 & 4 & 3 & 6 & 2 & 9 & 11 \\
\hline $1-2$ & 158 & 47 & 143 & 50 & 9 & 3 & 2 & 8 & 1 & 20 & 8 \\
\hline $2-3$ & 199 & 46 & 120 & 39 & 13 & 2 & 2 & 3 & 0 & 15 & 7 \\
\hline $3-4$ & 188 & 32 & 107 & 43 & 15 & 0 & 2 & 5 & 1 & 6 & 6 \\
\hline $4-5$ & 218 & 28 & 157 & 44 & 32 & 2 & 2 & 7 & 1 & 7 & 13 \\
\hline 5-6 & 126 & 11 & 62 & 36 & 4 & 2 & 0 & 2 & 0 & 4 & 4 \\
\hline Totals & 1899 & 349 & 1163 & 524 & 158 & 46 & 30 & 60 & 24 & 126 & 110 \\
\hline
\end{tabular}

Collections were conducted hourly from $6 \mathrm{pm}$ to $6 \mathrm{am}$ over 10 nights collections were made simultaneously with collections off human bait see Table 9. Total number of specimens collected =4,489; of the 1,899 An. sinensis collected 1,852 were An. sinensis, 41 An. peditaeniatus and 6 An. crawfordi

light (5.30 am - 5.45 am) and no human landing occurred after this time. In the collections off cattle and buffalo it was noted that anophelines rested before and after feeding on the vegetation surrounding these hosts.

\section{Larval habitats}

The preference for, and availability of, particular habitats can account for differences in the distribution, abundance, and seasonality of individual species. Table 13 lists the oviposition sites for the most common species in Khe Ngang and Hang Chuon. The main difference

Table 11 Night landing pattern for six Anopheles species collected off human bait in Khe Ngang village in the wet seasons (September- October) of 2003-2004

\begin{tabular}{cccc}
\hline & & \multicolumn{2}{c}{ Khe Ngang landing/person/hour } \\
\cline { 3 - 4 } Hour & No. of nights & An. sinensis $\mathbf{n}=\mathbf{6 4 8}$ & An. aconitus $\mathbf{n}=\mathbf{1 4 5}$ \\
\hline $6-7$ & 27 & 0.46 & 0.12 \\
$7-8$ & 27 & 0.55 & 0.23 \\
$8-9$ & 27 & 0.55 & 0.25 \\
$9-10$ & 27 & 0.96 & 0.37 \\
$10-11$ & 27 & 1.7 & 0.47 \\
$11-12$ & 27 & 1.4 & 0.19 \\
$12-1$ & 27 & 1.2 & 0.21 \\
$1-2$ & 27 & 1.2 & 0.30 \\
$2-3$ & 27 & 1.2 & 0.21 \\
$3-4$ & 27 & 1.6 & 0.14 \\
$4-5$ & 27 & 1.1 & 0.09 \\
$5-6$ & 27 & 0.5 & 0.10 \\
landing/person/night & 12.42 & 2.68 \\
\hline
\end{tabular}


Table 12 Night landing pattern for six Anopheles species collected off human bait in Hang Chuon village in the wet seasons (September- October) of 2004-2005

\begin{tabular}{cccccc}
\hline & & \multicolumn{5}{c}{ Hang Chuon landing/person/hour } \\
\cline { 3 - 6 } Hour & No. of Nights & An. dirus $\mathbf{n}=\mathbf{9 8}$ & An. harrisoni $\mathbf{n}=\mathbf{6 7}$ & An. maculatus $\mathbf{n}=\mathbf{2 6 7}$ & An. sawadwongporni $\mathbf{n}=\mathbf{3 9 1}$ \\
\hline $6-7$ & 27 & 0.115 & 0.17 & 1.03 & 0.95 \\
$7-8$ & 27 & 0.145 & 0.13 & 0.42 & 0.63 \\
$8-9$ & 27 & 0.20 & 0.07 & 0.27 & 0.44 \\
$9-10$ & 19 & 0.10 & 0.04 & 0.18 & 0.38 \\
$10-11$ & 19 & 0.15 & 0.10 & 0.08 & 0.32 \\
$11-12$ & 19 & 0.04 & 0.040 & 0.03 & 0.26 \\
$12-1$ & 14 & 0.12 & 0 & 0.11 & 0.34 \\
$1-2$ & 14 & 0.12 & 0.09 & 0.20 & 0.21 \\
$2-3$ & 14 & 0.13 & 0.06 & 0.11 & 0.20 \\
$3-4$ & 14 & 0.12 & 0.04 & 0.09 & 0.32 \\
$4-5$ & 14 & 0.03 & 0.11 & 0.13 & 0.30 \\
$5-6$ & 14 & 0.07 & 0.11 & 0.41 & 0.43 \\
landing/person/night & 1.29 & 0.93 & 3.06 & 4.68
\end{tabular}

between these two villages, with regards to larval habitats, was the presence of rice fields around Khe Ngang and the greater extent of riparian habitat around Hang Chuon. In Truong Xuan Commune rice is planted in the wet season during October - November and harvested in May, but pools remain in rice fields long after harvest. Anopheles sinensis had a significant associated with rice growing $\left(\chi^{2}=22.5, \mathrm{P}<0.001\right)$, which would explain its abundance around Khe Ngang. Rice fields are flooded in October but contain pools of water long after the rice is harvested in May, An. sinensis will use flooded rice fields but prefers the pools that were left post-harvest; thus $A n$. sinensis can occur year round but was more common in the dry season than the wet season. Anopheles harrisoni, An. maculatus, and An. sawadwongporni all had a significant association with pools in stream and river beds $\left(\chi^{2}>38.4, \mathrm{P}<\right.$ 0.001) and were more abundant in Hang Chuon, which has a more extensive net work of rivers and streams. Dry season conditions seem to favour the abundance of An. harrisoni (Table 8), of the 18 larval sites located for this species in Hang Chuon in the dry season of 2006 only one was found in the following wet season. However with $A n$. sawadwongporni there appeared to be no correlation between seasonal abundance and the availability of larval habitats, this species was more prolific in

Table 13 Larval habitats for the common anopheline species collected in Khe Ngang and Hang Chuon during 2004 2007

\begin{tabular}{|c|c|c|c|c|}
\hline \multirow[b]{2}{*}{ Species (Number of habitats located) } & \multicolumn{4}{|c|}{ Larval habitat used (\%) } \\
\hline & Rice fields & Ground pools & Riparian & Flooded grassland \\
\hline An. vagus (42) & $8(19.1)$ & $26(61.9)$ & $6(14.3)$ & $2(4.8)$ \\
\hline An. sinensis (40) & $25(62.5)$ & $12(30.0)$ & $1(2.5)$ & $2(5.0)$ \\
\hline An. maculatus (31) & $2(6.4)$ & $3(9.7)$ & $25(80.6)$ & $1(3.2)$ \\
\hline An. sawadwongporni (30) & 0 & 0 & $29(96.7)$ & $1(3.3)$ \\
\hline An. harrisoni (23) & 0 & $1(4.3)$ & $21(91.3)$ & $1(4.3)$ \\
\hline An. annularis (19) & $7(36.8)$ & $8(42.0)$ & $1(5.3)$ & $3(15.8)$ \\
\hline An. aconitus (19) & $6(31.6)$ & $8(42.0)$ & $3(15.8)$ & $2(10.5)$ \\
\hline An. philippinensis (15) & $5(33.3)$ & $5(33.3)$ & 0 & $5(33.3)$ \\
\hline An. barbirostris (10) & $2(20.0)$ & $2(20.0)$ & $6(60.0)$ & 0 \\
\hline An. peditaeniatus (7) & $4(57.1)$ & $3(42.9)$ & 0 & 0 \\
\hline An. kochi (8) & $7(87.5)$ & $1(12.5)$ & 0 & 0 \\
\hline An. nivipes (5) & $2(40.0)$ & $1(20.0)$ & 0 & $2(40.0)$ \\
\hline An. dirus (1) & 0 & 0 & $1(100)$ & 0 \\
\hline
\end{tabular}

Rice fields includes those flooded for cultivation and pools post-harvest, also included are associated pools used for regulating water in rice fields; ground pools includes buffalo wallows, borrow pits, natural depressions, fish ponds, and pools in drains; riparian habitat includes pools associated with rivers and streams, pools along the margins of rivers and streams, turbulence pits, pools in drying streams, rock pools; and flooded grassland includes water meadows inundated with water from irrigation runoff, flood water runoff, overflow from rivers and streams. 
the wet season but in 2006 nearly the same number of larval sites were found for this species in the dry season $(\mathrm{n}=14)$ as in the wet season $(\mathrm{n}=17)$. Of 42 larval habitats for An. maculatus and An. sawadwongporni located at Hang Chuon in 2006, both species co-habited in 13 sites. Anopheles vagus, a common and adaptable species, utilised a wide variety of ground pools and was found in all habitats. Anopheles dirus larvae were found in only one site - a small pool in a jungle stream - this collection was made in the dry season of 2004 but was not found there again at this site over the next three years.

\section{Vector status}

Specimens of all the common species collected off human and animal baits were assayed for CS protein and the findings presented in Table 14. Several species were found positive for CS protein; of these $A n$. sinensis was the main malaria vector in Khe Ngang, where it was most common, while An. harrisoni, An. maculatus and $A n$. sawadwongporni were the main vectors in Hang Chuon.

\section{Discussion}

In the Southeast Asian countries of Vietnam, Cambodia, Laos and Thailand the primary malaria vectors are An. dirus, An. minimus, An. maculatus, and An. sawadwongporni with the relative importance of each varying, depending on the ecology of the area where transmission is occurring [15-22]. Other species are occasionally incriminated: An. aconitus, An. jeyporiensis, An. philippinensis, An. nivipes, $A n$. barbirostris, and members of the $A n$. hyrcanus group $[16,19,21,22]$. One feature common to all these species is that they are zoophilic and are found more often feeding on cattle and buffalo than on humans
$[19,23,24]$; the only exception being $A n$. dirus, which has consistently been shown to be an anthropophilic species and for this reason is the most dangerous vector of all the species mentioned above $[16,18,19,21,25]$.

The low rate of malaria transmission found in the villages of Khe Ngang and Hang Chuon, two typical rural communities in north central Vietnam, was being maintained by a number of zoophilic species: An. sinensis, An. harrisoni, An. maculatus, An. sawadwongporni, An. aconitus, An. peditaeniatus, and An. philippinensis, This more or less reflects the findings of other workers in Southeast Asia $[15,17,21,22]$. Though in this study $A n$. sinensis was found to play a relatively major role in malaria transmission and $A n$. dirus was not found positive for CS antigen, though this might reflect the paucity of this species in the study area.

In Thailand and Laos, An. sinensis and other members of the Hyrcanus Group do not appear to play a role in malaria transmission; there are only two published records of them being possible vectors $[21,25]$. They are rarely recorded in large numbers [17,21-23,26,27], only in one village in Khammouane Province, Laos (on the border with Quang Binh Province, Vietnam) were members of this Group abundant, making up $44.2 \%$ of the catch off animal baits and $21.4 \%$ in HLC [19]. The reason for the low densities of $A n$. sinensis recorded in surveys conducted in Thailand and Laos is unknown; in this study in Truong Xuan Commune, An. sinensis was strongly associated with rice growing, an activity that is ubiquitous throughout Thailand and Laos. Anopheles sinensis is more common to the north east of Vietnam throughout China and the Korean Peninsula where it is a major vector of malaria (along with other members of the Hyrcanus Group) [27-29]. In most surveys where

Table 14 Anopheles species tested positive for circumsporozoite protein

\begin{tabular}{|c|c|c|c|c|}
\hline Species & No. tested & No. positive (SR) & Village & Collection method and malaria parasite species \\
\hline An. sinensis & 1442 & $12(0.01)$ & Khe Ngang & $\begin{array}{l}\text { human bait: } P f \times 4, P \vee 247 \times 2, P \vee 210 \times 1 \\
\text { animal bait: } P f \times 1, P \vee 247 \times 3, P \vee 210 \times 1\end{array}$ \\
\hline An. harrisoni & 997 & $3(0.003)$ & Hang Chuon & $\begin{array}{l}\text { animal bait: } \mathrm{Pf} \times 2 \\
\text { human bait: } \mathrm{Pf} \times 1\end{array}$ \\
\hline An. maculatus & 1112 & $2(0.002)$ & Hang Chuon & $\begin{array}{l}\text { human bait: } P f \times 1 \\
\text { animal bait: } P f \times 1\end{array}$ \\
\hline An. sawadwongporni & 1120 & $1(0.001)$ & Hang Chuon & human bait: Pf \\
\hline An. aconitus & 1539 & $1(0.0006)$ & Khe Ngang & human bait: Pf \\
\hline An. peditaeniatus & 131 & $1(0.008)$ & Khe Ngang & animal bait: Pv 247 \\
\hline An. philippinensis & 658 & $1(0.002)$ & Khe Ngang & human bait: Pv 247 \\
\hline An. vagus & 586 & 0 & & \\
\hline An. annularis & 366 & 0 & & \\
\hline An. kochi & 136 & 0 & & \\
\hline An. dirus & 123 & 0 & & \\
\hline An. minimus & 14 & 0 & & \\
\hline
\end{tabular}

Where Pf = Plasmodium falciparum and Pv = Plasmodium vivax (210 and 247 variant); mosquitoes were collected over the period 2004-2007. Where SR = sporozoite rate. 
Hyrcanus specimens have been collected there has been no attempt to separate the members of the Group $[16,19,21,25]$; this is due to major difficulties with the morphological identification of these species throughout their range in Southeast Asia and China [30,31]. It has been suggested that there is too much variation in many of the characters commonly used to assign affinities between members of this Group [31]. Certainly in this survey there were issues with separating species, with seven members of the Group being identified by morphology but this being resolved to three following molecular analysis.

Members of the Minimus Complex - An. minimus and An. harrisoni - have been found in Vietnam, though only $A n$. minimus has been incriminated as a vector [15]. Anopheles minimus is thought to occur throughout the country while $A n$. harrisoni is confined to the north (north of Quang Binh Province) [32], however the distribution of these two species is not well understood because their separation has been based on unreliable morphological wing characters [33]. Using DNA based identification technology [9], An. harrisoni has recently been recognised as occurring in central Vietnam with an apparent shift in dominance from $A n$. minimus to $A n$. harrisoni though the numbers collected and processed were small [34]. In this study, conducted in Quang Binh Province, north-central Vietnam over the period 2003-2007, An. harrisoni was the dominant species, accounting for $98.2 \%(1009 / 1028)$ of the $A n$. minimus s.l. collected whereas An. minimus made up only $1.8 \%$ (19/1028). This study also incriminates for the first time $A n$. harrisoni as a vector of malaria in Vietnam though as mentioned above this is a zoophilic species and its role in transmission is opportunistic.

The persistence of $P$. falciparum throughout the year will require continual human vector contact to be maintained. This is possible in Truong Xuan Commune due to both wet and dry seasons providing favourable conditions for the various vector species. Of the four most important vectors - An. sinensis, An. harrisoni, An. maculatus and An. sawadwongporni - An. sinensis occurred throughout the year but appeared to be more common in the dry season, $A n$. harrisoni was also more common in the dry season, whereas An. sawadwongporni was more common in the wet season and An. maculatus was found throughout the year.

While important in the local context of malaria transmission in Truong Xuan Commune none of the species reported on here appear to be efficient vectors as indicated by the overall low malaria transmission rates and low sporozoite rates. The main reason being the zoophilic behaviour of these species of mosquitoes. The close temporal association of cattle and buffalo to human habitation was not for any intended zooprophylactic purpose but simply for security and ownership. Not all households possessed cattle or buffalo and if far enough removed from these blood sources most of the anopheline species recorded here would readily feed on humans as indicated by the HLC for An. sinensis, An. aconitus, An. dirus, An. maculatus, An. sawadwongporni, and An. harrisoni. In Pakistan, where the main malaria vectors show zoophilic tendencies and cattle are kept close to houses, the inhabitants of such households appear to be at a higher risk from malaria infections as opposed to households without cattle [35]. This is due to cattle attracting larger numbers of mosquitoes into the household area and thus increasing human vector contact. This does not appear to be the case in Vietnam, in this study paired collections off buffalo and humans separated by only $15 \mathrm{~m}$ buffalo attracted $97.4 \%$ (4489/4610) of the anophelines collected and only $2.6 \%(121 / 4610)$ were diverted to humans (Tables 9 and 10). Thus, while unintended, cattle and buffalo in Khe Ngang and Hang Chuon do play a zooprophylactic role.

Two behavioral characteristics were observed in the anophelines in Truong Xuan Commune that will reduce the impact of a malaria control strategies involving indoor residual spraying (IRS) and the use of long lasting insecticidal nets (LLIN). The early night feeding (6 pm - 9 pm) of An. maculatus, An. sawadwongporni, $A n$. dirus, and An. harrisoni will allow avoidance of the insecticide through outdoor biting as village people are still active outdoors at these times and even if indoors prior to $9 \mathrm{pm}$ are not likely to be protected by a bed net. Similar early night feeding behaviour of these species has been noted in other parts of their range $[22,23,36,37]$. In Thailand there is evidence that these four species all show a pronounced excito-repellency response to DDT and pyrethroids [38,39]. While a shift to early night biting may be a way of allowing these species obtaining a blood meal outdoors and thus avoiding the insecticide treated surfaces. However these species, with the exception of $A n$. dirus, are essentially zoophilic and would be under little if any insecticidal pressure to change their behaviour. The second and more important issue is the large uncontrolled zoophilic component of the anopheline fauna that will enable anopheline numbers to remain high and at the same time provide sufficient numbers for the occasional feeding on humans to maintain malaria transmission. This zoophilic component will be unaffected by the use of IRS and LLIN. As the anopheline species collected from cattle and buffalo baits were found to rest on vegetation before and after feeding a possible control strategy would be the use of pyrethroids as a barrier spray on the vegetation directly surrounding the cattle and buffalo. Barrier spraying of vegetation has been used in various situations against a 
number of pest and vector species [40-42]. In Khe Ngang there are 48 houses and in Hang Chuon 26, but in Khe Ngang and Hang Chuon there are only four and five locations respectively where cattle and buffalo are kept at night. The area around the buffalo is approximately $4 \mathrm{~m} \times 5 \mathrm{~m}$; the area around the cattle varies with the number of cattle but the largest no bigger than $5 \mathrm{~m} \times 10 \mathrm{~m}$. The advantage of using barrier spraying in these villages in Truong Xuan is that mosquitoes are attracted and concentrated into a small area around the penned or tethered animals so only a small defined area would need to be sprayed and these are considerable less than the number of houses requiring spraying using conventional IRS. This would allow for multiple applications over a year to compensate for the poor residual effect of these insecticides applied in this manner $[42,43]$. This method of insecticide application would be more effective than the current permethrin IRS.

\section{Conclusion}

In the rural areas of Quang Binh Province, north central Vietnam, where the forest has been largely cleared for agriculture and the primary malaria vector $A n$. dirus is uncommon, malaria transmission was still maintained throughout the year by a number of secondary vectors An. sinensis, An. harrisoni, An. maculatus, An. sawadwongporni, An. aconitus, An. peditaeniatus, and An. philippinensis. In this study the use of DNA-based identification methods made it possible to accurately incriminate the vector species and to assign relevant transmission parameters such as, larval ecology, biting behaviour, host preference, and seasonal abundance patterns to the appropriate species. The vector species were all predominantly zoophilic and were not particularly effective vectors, their differing preferences for oviposition sites over the year allowed for low level but persistent year round malaria transmission. The attractiveness of cattle and buffalo for these mosquitoes tends to concentrate mosquitoes into small and well defined areas within the village and as the host seeking mosquitoes rest on vegetation, in the immediate vicinity of the animal host both before and after feeding, there is an opportunity to implement barrier spraying. This may have a greater impact on anopheline densities and species longevity than the currently used control methods of IRS and LLIN.

\footnotetext{
Acknowledgements

The authors readily acknowledge the excellent technical support of Pham Dinh Hai, Nguyen Xuan Minh, Bach Ngog Luyen, Truong Trong Quang, and Do Duy Tai from the Military Institute of Hygiene and Epidemiology, Hanoi. The authors wish to thank the Truong Xuan Commune Leaders for approving and supporting this work and all the staff of the Truong Xuan Health Station for allowing us to use the clinic as a base for our studies and in particular Nguyen Van Ninh for his microscopic diagnosis of malaria.
}

This study received financial support from the International Policy Division, Australian Defence Organisation. The opinions expressed herein are those of the author's and do not necessarily reflect those of the Australian Defence Organisation or any extant policy.

\section{Author details}

${ }^{1}$ Entomology Department, Military Institute of Hygiene and Epidemiology, Hanoi, Vietnam. ${ }^{2}$ School of Biological Sciences, University of Queensland, St Lucia, Queensland, 4072, Australia. ${ }^{3}$ CSIRO Entomology, Long Pocket Laboratories, Indooroopilly, Queensland, 4068, Australia. ${ }^{4}$ Military Preventive Medicine Centre, Ho Chi Minh City, Vietnam. ${ }^{5}$ Australian Army Malaria Institute, Gallipoli Barracks, Enoggera, Queensland 4051, Australia.

\section{Authors' contributions}

DMC and LQT coordinated and led the field and laboratory teams in the collection of specimens and the processing of specimens for species identification and circumsporozoite protein and contributed to the content of the manuscript. NWB provided intellectual input and support for the molecular identification of the anopheline species and contributed to content of the manuscript. NTHV carried out much of the processing of specimens for species identification and circumsporozoite protein. TLC, NVD, NXT and LNA all made substantial contributions to organising and supervising the collection of the field data. RDC designed the study, participated in the collection and processing of the specimens and drafted the manuscript. All authors have read and approved the final manuscript.

\section{Competing interests}

The authors declare that they have no competing interests.

Received: 28 April 2010 Accepted: 16 September 2010

Published: 16 September 2010

\section{References}

1. Hung LQ, de Vries PJ, Giao PT, Nam NV, Binh TQ, Chong MT, Quoc NTTA, Thanh TN, Hung LN, Kager PA: Control of malaria: a successful experience from Viet Nam. Bull World Health Organ 2002, 80:660-665.

2. Barat LM: Four malaria success stories: How malaria burden was successfully reduced in Brazil, Eritrea, India, and Vietnam. Am J Trop Med Hyg 2006, 74:12-16.

3. Morrow M, Nguyen QA, Caruana S, Biggs BA, Doan NH, Nong TT: Pathways to malaria persistence in remote central Vietnam: a mixed-method study of health care and the community. BMC Public Health 2009, 9:85.

4. Erhart A, Thang ND, Hung NQ, Toi LV, Hung LX, Tuy TQ, Cong LD, Speybroeck N, Coosemans M, D'alessandro U: Forest malaria in Vietnam: a challenge for control. Am J Trop Med Hyg 2004, 70:110-118.

5. Erhart A, Thang ND, Ky PV, Tinh TT, Overmeir CV, Speybroeck N, Obsomer V, Hung LX, Thuan LK, Coosemans M, D'alessandro U: Epidemiology of forest malaria in central Vietnam: a large scale cross-sectional survey. Malar J 2005, 4:58.

6. Sang NH, Dung NV, Thanh NX, Trung TN, Co TV, Cooper RD: Forest malaria in central Vietnam. Am J Trop Med Hyg 2008, 79:653-654.

7. Walton C, Handley JM, Kuvangkadilok C, Collin FH, Harbach RE, Baimai V, Butlin RK: Identification of five species of the Anopheles dirus complex from Thailand using allele-specific polymerase chain reaction. Med Vet Entomol 1999, 13:24-32.

8. Manguin S, Kengne P, Sonnier L, Harbach RE, Baimai V, Trung HD, Coosemans M: SCAR markers and multiplex PCR-based identification of isomorphic species in the Anopheles dirus complex in Southeast Asia. Med Vet Entomol 2002, 16:46-54.

9. Van Bortel W, Trung HD, Roelants P, Harbach RE, Backeljau T, Coosemans M: Molecular identification of Anopheles minimus s.l. beyond distinguishing the members of the species complex. Insect Mol Biol 2000, 9:335-340.

10. Walton C, Somboon P, O'Loughlin SM, Zhang S, Harbach RE, Linton YM, Chen B, Nolan K, Duong S, Fong MY, Vythilingum I, Mohammed ZD, Trung HD, Butlin RK: Genetic diversity and molecular identification of mosquito species in the Anopheles maculatus group using the ITS2 region of rDNA. Infect Genet Evol 2007, 7:93-102.

11. Walton C, Somboon P, Harbach RE, Zhang S, Weerasinghe I, O'Loughlin SM, Phompida S, Sochantha T, Tun-Lin W, Chen B, Butlin RK: Molecular identification of mosquito species in the Anopheles annularis group in southern Asia. Med Vet Entomol 2007, 21:30-35. 
12. Dusfour I, Blondeau J, Harbach RE, Vythilingham I, Baimai V, Trung HD, Sochanta T, Bangs MJ, Manguin S: Polymerase chain reaction identification of three members of the Anopheles sundaicus (Diptera: Culicidae) complex, malaria vectors in Southeast Asia. J Med Entomol 2007, 44:723-731.

13. Beebe NW, Maung J, van den Hurk AF, Ellis JT, Cooper RD: Ribosomal DNA spacer genotypes of the Anopheles bancroftii group (Diptera: Culicidae) from Australia and Papua New Guinea. Insect Mol Biol 2001, 10:407-413.

14. Beebe NW, Saul A: Discrimination of all members of the Anopheles punctulatus complex by polymerase chain reaction-restriction fragment length polymorphism analysis. Am J Trop Med Hyg 1995, 53:478-481.

15. Trung HD, Van Bortel W, Sochantha T, Keokenchanh K, Quang NT, Cong LD, Coosemans M: Malaria transmission and major malaria vectors in different geographical areas of Southeast Asia. Trop Med Int Health 2004, 9:230-237.

16. Vythilingam I, Phetsouvanh R, Keokenchanh K, Yengmala V, Vanisaveth V, Phompida S, Hakim SL: The prevalence of Anopheles (Diptera: Culicidae) mosquitoes in Sekong Province, Lao PDR in relation to malaria transmission. Trop Med Int Health 2003, 8:525-535.

17. Coleman RE, Sithiprasasna R, Kankaew P, Kiattibut C, Ratanawong S, Khuntirat B, Sattabongkot J: Naturally occurring mixed infection of Plasmodium vivax VK210 and P. vivax VK247 in Anopheles mosquitoes (Diptera: Culicidae) in western Thailand. J Med Entomol 2002, 39:556-559.

18. Vythilingam I, Sidavong B, Chan ST, Phonemixay T, Vanisaveth V, Sisoulad P, Phetsouvanh R, Hakim SL, Phompida S: Epidemiology of malaria in Attapeu Province, Lao PDR in relation to entomological parameters. Trans R Soc Trop Med Hyg 2005, 99:833-839.

19. Toma T, Miyagi I, Okazawa T, Kobayashi J, Saita S, Tuzuki A, Keomanila H, Nambanya S, Phompida S, Uza M, Takakura M: Entomological surveys of the malaria in Khammouane Province, Lao PDR, in 1999 and 2000. Southeast Asian J Trop Med Public Health 2002, 33:532-546.

20. Chareonviriyaphap T, Bangs MJ, Ratanatham S: Status of malaria in Thailand. Southeast Asian J Trop Med Public Health 2000, 31:225-237.

21. Rattanarithikul $R$, Konishi $E$, Linthicum KJ: Detection of Plasmodium vivax and Plasmodium falciparum circumsporozoite antigen in anopheline mosquitoes collected in southern Thailand. Am J Trop Med Hyg 1996, 54:114-121.

22. Harbach RE, Gingrich, Pang LW: Some entomological observations on malaria transmission in a remote village in northwestern Thailand. J Am Mosa Control Assoc 1987, 3:296-301.

23. Rattanarithikul R, Konishi E, Linthicum KJ: Observations on nocturnal biting activity and host preference of anophelines collected in southern Thailand. J Am Mosa Control Assoc 1996, 12:52-57.

24. Muenworn V, Sungvornyothin S, Kongmee M, Polsomboon S, Bangs MJ, Akathanakul P, Tanasinchayakul S, Prabaripai A, Chareonviriyaphap T: Biting activity and host preference of the malaria vectors Anopheles maculatus and Anopheles sawadwongporni (Diptera: Culicidae) in Thailand. J Vector Ecol 2009, 34:62-69.

25. Rosenberg $R$, Andre RG, Somchit L: Highly efficient dry season transmission of malaria in Thailand. Trans R Soc Trop Med Hyg 1990, 84:22-28.

26. Kobayashi J, Somboon P, Keomanila H, Inthavongsa S, Nambanya S, Inthakone S, Sato Y, Miyagi I: Malaria prevalence and a brief entomological survey in a village surrounded by rice fields in Khammouan province, Lao PDR. Trop Med Int HIth 2000, 5:17-21.

27. Li Z, Luo D, Liu X: Malaria characteristics and control in Henan, People's Republic of China. Southeast Asian J Trop Med Public Health 1995, 26:402-406.

28. Dapeng L, Deling L, Renguo Y, Peng L, Xueguang H, Aimin L, Lei W, Changyin G, Shaowen Z, Hongru H, Leyuan S: Alphamethrin-impregnated bed nets for malaria and mosquito control in China. Trans $R$ Soc Trop Med Hyg 1994, 88:625-628.

29. Coleman RE, Kiattibut C, Sattabongkot J, Ryan J, Burkett DA, Kim HC, Lee WJ, Klein T: Evaluation of Anopheline mosquitoes (Diptera:Culicidae) from the Republic of Korea for Plasmodium vivax circumsporozoite protein. J Med Entomol 2002, 39:244-247.

30. Reid JA: The Anopheles hyrcanus Group in South-East Asia (Diptera: Culicidae). Bull Entomol Res 1953, 44:5-76.

31. Harrison BA, Southeast Asia Mosquito Project: A new interpretation of affinities within the Anopheles hyrcanus Complex of Southeast Asia. Mosq Syst 1972, 4:73-83.
32. Garros C, Van Bortel W, Trung HD, Coosemans M, Manguin S: Review of the Minimus Complex of Anopheles, main malaria vector in Southeast Asia: from taxonomic issues to vector control strategies. Trop Med Int Health 2006, 11:102-114.

33. Cuong DM, Van NTH, Tao LQ, Chau TL, Anh LN Thanh NX, Cooper RD: Identification of Anopheles minimus complex and related species in Vietnam. Southeast Asian J Trop Med Public Health 2008, 38:827-831.

34. Garros C, Marchand RP, Quang NT, Hai NS, Manguin S: First record of Anopheles minimus $\mathrm{C}$ and significant decrease of An. minimus $\mathrm{A}$ in central Vietnam. J Am Mosa Control Assoc 2005, 21:139-143.

35. Bouma M, Rowland M: Failure of passive zooprophylaxis: cattle ownership in Pakistan is associated with a higher prevalence of malaria. Trans R Soc Trop Med Hyg 1995, 82:351-353.

36. Chareonviriyaphap T, Parbaripai A, Bangs MJ, Aum-Aung B: Seasonal abundance and blood feeding activity of Anopheles minimus Theobald (Diptera: Culicidae) in Thailand. J Med Entomol 2003, 40:876-881.

37. Sungvornyothin S, Kongmee M, Muenvorn V, Polsomboom S, Bangs MJ, Prabaripai A, Tantakom S, Chareonviriyaphap T: Seasonal abundance and blood feeding activity of Anopheles dirus sensu lato in western Thailand. J Am Mosa Control Assoc 2009, 25:425-430.

38. Chareonviriyaphap T, Prabaripai A, Bangs MJ: Excito-repellency of deltamethrin on the malaria vectors, Anopheles minimus, Anopheles dirus, Anopheles sawadwongporni, and Anopheles maculatus, in Thailand. J Am Mosa Control Assoc 2004, 20:45-54.

39. Muenworn V, Akathanakul P, Bangs MJ, Prabaripai A, Chareonviriyaphap T: Insecticide-induced behavioral response in two populations of Anopheles maculatus and Anopheles sawadwongporni, malaria vectors in Thailand. J Am Mosq Control Assoc 2006, 22:689-698.

40. Britch SC, Linthicum KJ, Wynn WW, Walker TW, Faroog M, Smith VL, Robinson CA, Lothrop BB, Snelling M, Gutierrez A, Lothrop HD: Evaluation of barrier treatments on native vegetation in a southern California desert habitat. J Am Mosa Control Assoc 2009, 25:184-193.

41. Perich MJ, Tidwell MA, Dobson SE, Sardelis MR, Zaglul A, Williams DC: Barrier spraying to control the malaria vector Anopheles albimanus: laboratory and field evaluation in the Dominican Republic. Med Vet Entomol 1993, 7:363-368.

42. Amoo AOL, Xue R, Qualls WA, Quinn BP, Bernier UR: Residual efficacy of field-applied permethrin, $d$-phenothrin, and resmethrin on plant foliage against adult mosquitoes. J Am Mosq Control Assoc 2008, 24:543-549.

43. Anderson A, Apperson CS, Knake R: Effectiveness of mist-blower applications of malathion and permethrin to foliage as barrier sprays for salt marsh mosquitoes. J Am Mosq Control Assoc 1991, 7:116-117.

doi:10.1186/1475-2875-9-259

Cite this article as: Do Manh et al:: Vectors and malaria transmission in deforested, rural communities in north-central Vietnam. Malaria Journal 2010 9:259.

\section{Submit your next manuscript to BioMed Central and take full advantage of:}

- Convenient online submission

- Thorough peer review

- No space constraints or color figure charges

- Immediate publication on acceptance

- Inclusion in PubMed, CAS, Scopus and Google Scholar

- Research which is freely available for redistribution

Submit your manuscript at www.biomedcentral.com/submit
C Biomed Central 